\title{
Interaction between physical activity and diet: implications for blood pressure management in primary care
}

\author{
BM Margetts ${ }^{1}$, P Little $^{2}$ and D Warm ${ }^{1,3}$ \\ ${ }^{1}$ Institute of Human Nutrition and ${ }^{2}$ Department of Primary Medical Care, University of Southampton, Southampton \\ General Hospital, Level B, South Academic Block, SO16 6YD Southampton, UK \\ ${ }^{3}$ Unit for Preventive Nutrition, Karolinska Institute, Sweden
}

Accepted 3 June 1999

\begin{abstract}
Objectives: This review summarises the evidence for the effectiveness of primary care based interventions of diet and physical activity aimed at reducing blood pressure. Background: As blood pressure rises so does the risk of heart disease and stroke. There is a large literature on the effects on blood pressure of changing various aspects of diet either as single nutrient interventions, patterns of food consumption, or the addition of dietary supplements (potassium, magnesium, and fish oil). Controlled trials have been undertaken to assess the relative benefits of lifestyle changes in activity (walking etc) compared with more structured exercise programmes. There is sufficient evidence to suggest that changes in diet and activity under controlled conditions can reduce blood pressure and delay or reduce the need for drug treatment in subjects who are hypertensive. What is less clear is how to achieve these lifestyle changes in the primary care setting as part of routine clinical management. Results: There have been a number of systematic reviews undertaken to evaluate the evidence. The interventions were either delivered alone or in combination with other advice, either with or without aids, and by various practice nurse staff (GP, nurse, Dietitian); follow-up varied from 3 months to a year. Compliance with the advice was generally not measured. The variability in the quality of the studies and interventions made it difficult to draw conclusions: any effects seen tended to be small.

Conclusions: Equivocal results (non statistically significant reductions) should not be considered as proof of no effect without careful consideration of the effects of chance, bias and confounding, and without better measures of compliance. There is little debate that, under investigator control, blood pressure can be reduced by changes in diet and activity. Changes to a 'healthy' diet (low in total and saturated fat; energy intake balanced with expenditure to maintain or achieve optimal body weight; low in salt; high in fruits, vegetables, legumes; and whole grains) and increases in modest levels of physical activity (walking etc) would be expected to reduce blood pressure by between two and four mmHg. A shift in the population distribution of this order would be expected to have a substantial impact on population mortality patterns and could be achieved cost-effectively in primary care.
\end{abstract}

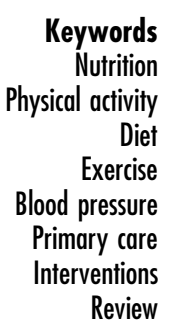

\section{Key messages}

- There is good evidence that under carefully controlled conditions lifestyle changes can reduce blood pressure, at least in those with higher blood pressures. Most trials have focused on single nutrients or a supplement approach and few have addressed the benefits of a 'healthy diet' with increased consumption of vegetables and fruits, together with increased levels of physical activity.

- Effectiveness trials in primary care have produced mixed results, but suggest that dietary advice can be a cost-effective approach to reducing or delaying the need for a pharmacological approach to control high blood pressure. It is difficult to draw firm conclusions because of the limited number and the non-specific nature of the interventions used.

- Further research is required to assess the benefits of increased vegetable and fruit consumption and physical activity on blood pressure using primary care settings.

\section{Introduction}

Cardiovascular disease rates have fallen in North America, Australia, Japan and Western Europe over the last twenty years ${ }^{1}$, but in many developing countries and the former socialist republics rates are 
rising $^{2}$. The 1997 and 1998 World Health Reports indicated that in 1997 of a global total of 52.2 million deaths, 15.3 million were caused by circulatory diseases (7.2 million of which were coronary heart disease [CHD]); of whom about 10 million occurred in the developing world ${ }^{3,4}$. By 2020 heart disease will be the leading cause of the global burden of disease in developing countries ${ }^{2}$. Although the age-specific incidence of stroke may be falling in many developed countries, given the rise in the total elderly population, the disease burden caused by the total numbers of strokes is rising 5 .

It is clear that stroke and CHD have multiple determinants, and studying any risk factor alone in isolation may be misleading, but there is little debate that elevated blood pressure is related to increased risk of stroke and heart disease ${ }^{5}$. Population shifts in the distribution of blood pressure of the order of $5 \mathrm{mmHg}$ would be expected to reduce the incidence of stroke by $26 \%$ and heart disease by $15 \%$, although there is probably a continuous curve-linear relationship between blood pressure and subsequent risk, suggesting any reduction in blood pressure may be beneficial ${ }^{5}$. Most evidence for the benefits and risks of lowering blood pressure comes from studies in patients selected on the basis of high blood pressure; it is therefore not possible to extrapolate about treatment effects to individuals with lower blood pressure. There is a strong rationale for expecting that high-risk patients without hypertension would benefit from lowering their blood pressure ${ }^{5}$. Extensive guidelines have recently been published for the management of hypertension; including the role of non-pharmacological interventions (lifestyle measures) and are summarised in Table $1^{5}$.

The control of hypertension has improved in many countries over the last few decades. The Health Examination Surveys in the United States showed that from the late 1970's to the late 1980's the prevalence of hypertensive patients who had their blood pressure controlled to below $140 / 90 \mathrm{mmHg}$ rose from $10 \%$ to $27 \%{ }^{6}$. In the UK in 1994 only about $6 \%$ of hypertensive patients had their high blood pressure under control $^{7}$. From 1958 to 1989 the rate of use of antihypertensive medication rose from $2.3 \%$ to $24.6 \%$ in participants in the Framingham Heart Study ${ }^{8}$. The current guidelines advocate a non-pharmacological or lifestyle approach before drug treatment is instigated, but this does not appear to be widely followed ${ }^{5}$.

Research to date has tended to focus on the effects of diet on blood pressure, with the assumption that changes in blood pressure would lead to changes in CHD mortality. The recent results from the Lyon Diet Heart Study ${ }^{9}$ suggested that a Mediterranean diet in patients who have survived a first myocardial infarction could reduce cardiac deaths by $65 \%$ (RR 0.35 , 95\%CI 0.15-0.83) after a four year follow up. Blood pressure and serum cholesterol were shown to have independent effects on risk and to be joint predictors of recurrence. Major dietary changes appeared to be changes in $\mathrm{n} 3$ and $\mathrm{n} 6$ fatty acids; both control and experimental diets had a low \% energy from fat although the intervention group had a lower level than controls $33.6 \%$ compared with $30.4 \%$ respectively, difference $p=0.002$ ).

A recent study by Ascherio and others showed that potassium, magnesium, and fibre had significant effects on protecting against stroke, particularly in those who were hypertensive ${ }^{10}$. An associated review suggested that the best way to achieve a high intake of these dietary components was by eating a diet rich in fruits and vegetables ${ }^{11}$. There is good evidence that early life events during fetal development can have long term effects on the level of blood pressure; poor fetal nutrition leads to higher adult blood pressure $^{12}$. Despite this early setting of blood pressure it is not

Table 1 WHO-ISH 1999 guidelines related to lifestyle measures (5) ${ }^{44}$ :

Lifestyle measures (or non-pharmacological
treatments) are used for a number of complementary reasons

Lifestyle and blood pressure recommendations
- To lower the blood pressure in the individual patient.

- To reduce the need for antihypertensive drugs and maximise their efficacy.

- To address the other risk factors present.

- For primary prevention of hypertension and associated cardiovascular disorders in populations.

- It is important that lifestyle measures be instituted within the framework of a structured plan that includes the use of counselling and monitoring by appropriate health professionals such as nurses, dietitians, clinical psychologists and other therapists, as well as the responsible physician.

- Recommendations should be tailored for each individual and greater use should be made of modern and well-validated counselling techniques.

- Lifestyle measures that are widely agreed to lower the blood pressure and that should be considered in all patients in whom they may apply are weight reduction, reduction of excessive alcohol consumption, reduction of high salt intake and increase in physical activity.

- Particular emphasis should be placed on cessation of smoking and on healthy eating patterns that contribute to the treatment of associated risk factors and cardiovascular diseases. 
disputed that blood pressure can be changed in later life by either pharmacological or non-pharmacological means, and that the level of change achievable is of public health benefit to the population.

This paper focuses on the evidence for the effects of diet and physical activity on blood pressure. After reviewing the randomized controlled trial data, evidence of the effects seen in pragmatic trials undertaken in the primary care setting will be summarised. The aim of this review is to establish whether there is any evidence to support lifestyle interventions in primary care that may be feasible and cost-effective for delivery in routine practice.

\section{Controlled trials}

\section{Diet}

This brief review will only discuss results from randomized controlled trials because they provide the best evidence for the effects of change in diet on blood pressure. Many authors have extensively reviewed the literature elsewhere; here we will only summarise the main consensus results from these reviews ${ }^{5,13-19}$. The type of dietary changes used may be broadly grouped into: individual nutrient studies (either increasing or decreasing intake); complex dietary changes in food patterns; or interventions using supplements. Almost every conceivable aspect of diet has been studied, either alone or in combination with a whole range of changes in other lifestyle risk factors (such as weight, alcohol, physical activity, smoking, and stress management).

Complex dietary changes, such as changing to a vegetarian dietary pattern, have been shown to be effective in lowering blood pressure ${ }^{20-21}$. The DASH randomized trial assessed the effect of either a diet rich in fruit and vegetables, or a diet rich in fruit and vegetables and low fat dairy foods and with a reduced saturated fat and total fat and cholesterol (combination diet $)^{22,23}$. This study suggested that the combination diet was more effective, particularly in African Americans compared with the general population $(6.8 \mathrm{mmHg}$ v. $3.0 \mathrm{mmHg}$ ), and in hypertensive compared with non-hypertensive subjects $(11.4 \mathrm{mmHg} \mathrm{v}$. $6.8 \mathrm{mmHg}$ ). Weight and salt intake were not changed in either group in this study. The TONE study showed that sodium restriction and weight loss in 60-80 year old obese participants reduced the need for drug treatment and improved blood pressure control ${ }^{24}$. A recent study suggested that regular fish consumption might enhance the effects of weight reduction in hypertensive patients $^{25}$

From these complex dietary change studies it is not possible to draw any conclusions about the effects of changes in individual components in the diet. It now seems likely that the effects of complex dietary changes depend on a combination of the effects of fruit, vegetables, fibre, and low saturated fat intake, with or without changes in energy balance (increased physical activity and /or reduced energy intake) that may alter body weight.

The effects of these changes will almost certainly alter intakes of potassium, sodium, calcium, magnesium, and probably most other nutrients. The evidence argues for a whole diet approach to lifestyle change, rather than focusing on a single nutrient approach.

\section{Exercise/physical activity}

This literature is complex and potentially confusing because different studies have used different measures of exercise and or physical activity. These issues are covered elsewhere; there is now some agreement about how physical activity should be defined and measured in a standardised way that should make reviewing the literature easier in the future.

Hillsdon and Thorogood reviewed studies aimed at promoting physical activity ${ }^{26}$. They found that interventions that encourage walking and that did not require attendance at a facility were most likely to lead to sustainable increases in overall physical activity. Brisk walking appeared to have the greatest potential for increasing activity levels in those adults who were currently sedentary.

In 1990, Berlin and Colditz reviewed the evidence for a difference in CHD risk between sedentary and active groups ${ }^{27}$. Based on data from 27 cohort studies they estimated that the sedentary groups were nearly twice as likely as the more active groups to have CHD.

Mulrow and Jackson reviewed the evidence from 9 randomized controlled trials in 245 people aged $29-72$ years ${ }^{14}$. The trials were of moderate $(60 \%$ VO2 max) activity ( $47 \mathrm{~min}$. per session for three days a week for 18 weeks); overall they suggested that the moderate activity was associated with a net beneficial effect of about $4 \mathrm{mmHg}$ of systolic blood pressure. Dunn et $a l .{ }^{28}$ compared the effects on blood pressure of six months of intensive intervention (either as structured exercise or lifestyle group) followed by 18 months of maintenance intervention in previously sedentary individuals. The exercise intervention subjects were expected to achieve $50-80 \%$ of $\mathrm{VO} 2$ maximal aerobic power for 20-60 min. for at least three sessions a week. The lifestyle group was advised to accumulate at least $30 \mathrm{~min}$. of moderate intensity physical activity on most days of the week. Both lifestyle and structured groups achieved about a $5 \mathrm{mmHg}$ reduction in diastolic blood pressure.

\section{Primary care based pragmatic trials}

There is good evidence that under carefully controlled conditions lifestyle changes can reduce blood pressure, at least in those with higher blood pressures. There is 
less evidence to support the practical application of this evidence to routine care (29-32 for reviews). Here we will present a summary of the main findings and focus more on the issues raised by these studies.

\section{Diet \& physical activity: lifestyle advice (Table 2)}

Ashendon et al. reviewed all available literature on diet and activity interventions in general practice ${ }^{32}$. They identified 10 studies that assessed the effect of diet (six studies with diet alone and 4 with general lifestyle interventions all of these included activity and were included in the activity analysis as well) and 6 exercise/ activity trials ( 5 with general lifestyle advice and one that assessed activity alone), although not all of these measured blood pressure as an outcome. It is thus more realistic to describe the evidence for the effects of lifestyle changes in general, rather than diet or activity changes alone. Ashendon et al. developed a scoring system to judge the scientific quality of each study. They concluded, "there is clear evidence that GP-based health programmes have modest and variable effects on health outcomes. For this change to translate into a useful public health effect either a greater proportion of GPs need to offer lifestyle advice routinely and repeatedly or GPs should direct their efforts towards high-risk groups where the potential for substantial change may be greater".

Table 2 summarises the main findings from studies that used a randomized design and complied with the principles of good study design ${ }^{29}$. Roe and others ${ }^{29}$ have summarised these studies in more detail, except for the most recent secondary prevention trial by Campbell et al. ${ }^{33}$ and Pritchard et al. ${ }^{36}$. Most of the interventions have been in the form of lifestyle advice and support. The intensity and content of the interventions used in these studies have varied from detailed tailored packages developed by negotiation with the subjects to, by leaflets only. In some studies the only intervention was to have risk factors measured. Few have measured diet with a validated measure; none have measured activity with a validated measure. An accurate measure of compliance is not possible in these studies, so it is difficult to interpret what has actually been delivered to each individual. The assumption must be made that if there is a difference between intervention and control group that the intervention has had an effect. Where there is no statistically significant difference between treatment and control, however, it may be unreasonable to conclude that the intervention has not worked. It may be that the intervention was not properly delivered in the right amount at the right time, or the power of the study was too low (generally not assessed in most studies) to detect a biologically significant difference. Most interventions have been in the form of information that individuals are expected to act upon. It is well known that there is a complex link between knowledge, attitudes and behaviour, and it is an assumption that increasing knowledge, even in a negotiated and patient lead approach, will lead to behaviour change. This assumption may not always be appropriate.

Table 2 Summary of trials of lifestyle change in primary care

\begin{tabular}{|c|c|c|c|}
\hline Study & Population/design & $\begin{array}{c}\text { Change/measured } \\
\text { exposure } \\
\text { (Difference treat-control) }\end{array}$ & $\begin{array}{l}\text { Difference in BP change } \\
\text { (mmHg) between } \\
\text { treatment and control }\end{array}$ \\
\hline \multicolumn{4}{|l|}{ Primary prevention } \\
\hline Family Heart Study (33) & $\begin{array}{l}26 \text { Practices in } 13 \text { towns: } 13 \text { intervention (with an } \\
\text { internal comparison) and } 13 \text { external comparison } \\
\text { practices: } 12472 \text { subjects: } 90 \text { min nurse interview } \\
\text { with take home materials, plus follow-up according } \\
\text { to risk and referral }\end{array}$ & Diet effect not measured & $\begin{array}{l}\text { SBP } \\
\text { External } \downarrow 7.5 \\
\text { Internal } \downarrow 7.3 \\
\text { DBP } \\
\text { External } \downarrow 2.5 \\
\text { Internal } \downarrow 3.5\end{array}$ \\
\hline Roderick et al. (34) & $\begin{array}{l}473 \text { from } 4 \text { practices: dietary advice (negotiated } \\
\text { advice at } 6 \text { weeks, } 3 \text { months, } 6 \text { months and } 12 \\
\text { month health check)/483 from } 4 \text { practices usual } \\
\text { care (leaflets); } 12 \text { month health check only }\end{array}$ & $\begin{array}{l}\text { Significant } \\
\text { Fibre } \uparrow, \% \text { energy from fat } \downarrow \text {; } \\
\text { P/S ratio } \uparrow\end{array}$ & $\begin{array}{l}\mathrm{SBP} \downarrow 0.59(-2.2-0.8) \\
\mathrm{DBP} \uparrow 0.09(-3.1-5.2)\end{array}$ \\
\hline OXCHECK (35) & $\begin{array}{l}5 \text { Practices in Bedfordshire: } 2136 \text { patients invited } \\
\text { for re-examination in second and third years versus } \\
3988 \text { patients attending for initial screen for first } \\
\text { time at either second or third year }\end{array}$ & $\begin{array}{l}\text { Accesses using DINE (44) } \\
\text { Exercise }>1 / \text { month } \uparrow \\
\text { Drink less full fat milk } \uparrow \\
\text { Use less butter } \uparrow\end{array}$ & $\begin{array}{l}\mathrm{SBP} \downarrow 2.8(1.3-4.4) \\
\mathrm{DBP} \downarrow 1.8(0.9-2.8)\end{array}$ \\
\hline Pritchard et al. (36) & $\begin{array}{l}1 \text { Practice in Western Australia; } 75 \text { men and } 198 \\
\text { women; high risk: control (baseline results given) } \\
\text { versus GP+dietitian or dietitian alone for } 6 \\
\text { consultations over } 1 \text { year }\end{array}$ & $\begin{array}{l}\text { Food records and diet } \\
\text { history }\end{array}$ & $\begin{array}{l}\text { Mean blood pressure } \\
\text { GP+ dietitian } \downarrow 12 \\
\text { Dietitian alone } \downarrow 7\end{array}$ \\
\hline \multicolumn{4}{|l|}{ Secondary prevention } \\
\hline Campbell et al. 1998 (33) & $\begin{array}{l}\text { All had diagnosis of coronary heart disease: } \\
673 \text { intervention attended nurse run clinics for } 12 \\
\text { months with negotiated behavioural change after } \\
\text { measuring behavioural risk } 670 \text { control }\end{array}$ & $\begin{array}{l}\text { Assessed using DINE } \\
\text { Exercise } \uparrow 67 \% \\
\text { Low fat diet } \uparrow 47 \%\end{array}$ & $\begin{array}{l}\text { \% appropriate treatment } \\
\text { Treatment } \\
\uparrow 9.8 \%(7.0-12.6) \\
\text { Control } \\
\uparrow(0.2 \%(-2.7-3.0)\end{array}$ \\
\hline
\end{tabular}




\section{Public health issues}

The recent WHO-ISH guidelines for the management of hypertension concluded "that in order to improve physician performance and other health outcomes, it is necessary to put in place a range of measures reaching locally into the practice site and involving local medical practitioners in an active way" ${ }^{\prime 5}$. Guidelines have been established to improve effectiveness for many conditions managed in primary care to such an extent that many GPs feel confused and overwhelmed. A number of groups have been established to try to help ${ }^{38}$.

There are two approaches, not necessarily mutually exclusive, that can be adopted: population or primary prevention or targeted or secondary prevention. The former assumes that the whole population will benefit from lifestyle advice and that the effort involved is simple and cost-effective. The latter, targeted approach assumes that lifestyle advice is more effective if directed more specifically to a high-risk group who will be more motivated to act on the advice because they have been labelled 'high-risk'. Advice directed towards the whole population may not seem relevant to most people, and therefore not be acted upon because people assume that the advice does not apply to them, or that they are not at risk ${ }^{39}$.

Does the expertise, time and facilities exist in primary care for the assessment, intervention and follow-up required to translate the findings from controlled clinical trials into routine care? The studies that have assessed the effects of simple screening, health checks or leaflets used in primary care suggest that small changes can be achieved, the question remains as to whether these small changes can be sustained and translated into bigger effects on mortality. It is our view that small (10-15\%) changes in risk factors may indeed be cost-effective and well worthwhile. We feel that more tailored and evidence based action related to individual dietary patterns may be effective in reducing blood pressure in those with elevated blood pressure. It is less certain if this applies to a population strategy to shift the whole distribution.

It has recently been shown that it is cost-effective to increase physical activity in middle-aged individuals who are currently inactive ${ }^{40}$. Barriers to the promotion of physical activity include lack of standard protocols, lack of success in the counselling role, lack of appropriate staff training (GP, nurse). If GPs are more physically active themselves they will be more likely to promote physical activity ${ }^{41}$. In the same study, as little as two extra minutes per consultation (10-12 min.) was enough to double the likelihood that a nurse promoted physical activity.

McAvoy et al $^{42}$ showed that despite increasing workloads, GPs remain positive about health promotion and lifestyle counselling; but highlighted the need for more training and support for lifestyle intervention. Of the 230 GPs surveyed only $16 \%$ and $9 \%$ respectively always collected information about exercise and diet/ nutrition respectively; but 63 and 61\% said they did it as indicated. 29\% and 20\% of GPs felt that they were effective or very effective at helping patients to exercise regularly or avoid excess weight, but over half felt that they had the potential to influence exercise and avoid excess weight. We have recently developed a validated and simple tool for assessing diet in primary care that may aid an evidence-based approach to counselling ${ }^{43}$.

In conclusion, there is good evidence that lifestyle changes can be effective in reducing the prevalence of high blood pressure, and that with the right supportive environment the primary care setting can be a costeffective setting for either primary or secondary prevention.

\section{References}

1 Uemura K, Pisa Z. trends in cardiovascular disease mortality in industrialised countries since 1950. Wld Hlth Statist Quart. 1988; 41: 155-168.

2 Murray CJL, Lopez AD, eds. The Global Burden of Disease. A comprehensive assessment of mortality and disability from diseases, injuries, and risk factors in 1990 and projected to 2020. World health Organization, Harvard University Press, 1996.

3 World health Organization. The World Health Report 1997. Geneva, World health Organization 1997.

4 World health Organization. The World Health Report 1998. Geneva, World health Organization 1998.

5 WHO-ISH Hypertension guidelines Committee. 1999 World health Organization-International Society of Hypertension Guidelines for the Management of Hypertension.

6 Burt VL, Cutler JA, Higgins M, et al. Trends in the prevalence, awareness, treatment, and control of hypertension in the adult US population. Data from the Health Examination Surveys, 1960-1991. Hypertension 1995; 26: 60-69.

7 Colhoun Hm, Dong W, Poulter NR. Blood pressure screening, management and control in England: results from the Health survey for England. J. Hypertens 1998; 16: $747-752$.

8 Mosterd A, D'Agostino RB, Silbershatz H, et al. Trends in the prevalence of hypertension, antihypertensive therapy, and left ventricular hypertrophy from 1950 to 1989. N. Engl. J. Med. 1999; 340: 1221-1227.

9 de Lorgeril M, Salen P, Martin J-L, Monjuad I, Delaye J, Mamelle N. Mediterranean Diet, Traditional Risk Factors, and the rate of Cardiovascular Complications After Myocardial Infarction. Final report of the Lyon Diet Heart Study. Circulation 1999; 99: 779-785.

10 Ascherio A, Rimm EB, Hernan MA, et al., Intake of potassium, magnesium, calcium, and fiber and risk of stroke among US men. Circulation 1998; 352 (suppl 3): $15-8$.

11 Suter PM. The effects of potassium, magnesium, calcium, and fiber on risk of stroke. Nutrition Reviews 1999; 57 : 84-91.

12 Barker DJP. Mothers, Babies and Health in Later Life. Second edition. Edinburgh, Churchill Livingstone 1998.

13 Brunner E, White I, Thorogood M, Bristow A, Curle D, Marmot M. Can dietary interventions change diet and cardiovascular risk factors? A meta-analysis of randomized controlled trials. Am. J. Public Health 1997; 87: 1415-1422. 
14 Mulrow C, Jackson R. Managing primary hypertension. Clinical Evidence 1999 (in press).

15 Law MR. Epidemiological evidence on salt and blood pressure. Am. J. bypertens. 1997; 10: 42s-45s.

16 Cutler JA, Follman D, Elliot P, Suhl I. An overview of randomized trials of sodium reduction and blood pressure. Hypertension 1991; 17 (suppl I): 27-33.

17 Cappuccio FP, MacGregor GA. Does potassium supplementation lower blood pressure? A meta analysis of published trials. J. Hypertens. 1991; 9: 465-473.

18 Cappuccio FP, Siano A, Strazzullo P. Oral calcium supplementation and blood pressure: an overview of randomized controlled trials. J. Hypertens. 1991; 7: 941-946.

19 Feldman EB. Nonpharmacologic interventions successfully treat hypertension in older persons. Nutrition reviews 1998; 56: 341-343.

20 Beilin LJ, Rouse IL, Armstrong BK, Margetts BM, Vandongen R. Vegetarian diet and blood pressure levels: incidential or caual association. Am. J. Clin. Nutr. 1988; 48: 806-10.

21 Margetts BM, Beilin LJ, Vandongen R, Armtstrong BK. Vegatarian diet in mild hypertension: a randomized controlled trial. BMJ 1986; 293: 1468-1471.

22 Appel LJ, Moore TJ, Obarzanek E, et al. A clinical trial of dietay patterns on blood pressure. N. Engl. J. Med. 1997; 336: $1117-24$.

23 Svetky LP, Simons-Morton D, Vollmer WM, et al. Effects of dietary patterns on blood pressure: subgroup analysis of the Dietary Approaches to Stop Hypertension (DASH) randomized clinical trial. Arch. Int. Med. 1999; 159: 285-93.

24 Whelton PK, Appel LJ, Espeland MA, et al. Sodium reduction and weight loss in the treatment of hypertension in older persons. A randomized controlled trial of nonpharmacologic interventions in the elderly (TONE). JAMA 1998; 279: 839-846.

25 Bao DG, Mori TA, Burke V, Puddey IB, Beilin LJ. Effects of dietary fish and weight reduction on ambulatory blood pressure in overweight hypertensives. Hypertension 1998; 32: 710-717.

26 Hillsdon M, Thorogood M. A systematic review of physical activity promotion strategies. Br. J. Sports Med. 1996; 30: 84-89.

27 Berlin JA, Colditz GA. A meta-analysis of physical activity in the prevention of coronary heart disease. Am. J. Epidemiol. 1990; 132, 31: 639-646.

28 Dunn AL, marcus BH, Kampert JB, garcia ME, Kohl HW $3^{\text {rd }}$, Blair SN. Comparison of lifestyle and structured interventions to increase physical activity and cardiorespiratory fitness: a randomized trial. JAMA 1999; 281: 327-334.

29 Roe L, Hunt P, Bradshaw H, Rayner M. health promotion interventions to promote healthy eating in the general population: a review. London, Health Education Authority, 1997.

30 Ebrahim S, Smith GD. Systematic review of randomized controlled trials of multiple risk factor interventions for preventing coronary heart disease. Br. Med. J. 1997; 314 16666-166674.

31 Little P, Margetts BM. The importance of diet and physical activity in the treatment of conditions managed in general practice. Br. J. Gen. Prac. 1996; 46: 187-192.

32 Ashendon R, Silagy C, Weller D. A systematic review of the effectiveness of promoting lifestyle change in general practice. Family Practice 1997; 14: 160-176.

33 Campbell NC, Ritchie LD, Thain J, deans HG, Rawles JM, Squair JL. Secndary prevention in coronary heart disease: a randomized trial of nurse lead clinics in primary care. Heart 1998; 80: 447-452.

34 Family Heart Study. Randomised controlled trial evaluating cardiovascular screening and intervention in general practice: principal results of British family heart study. $B M J$ 1994; 308: 313-320.

35 Roderick P, Ruddock V, Hunt P, Miller G. A randomized trial to evaluate the effectiveness of dietary advice by practice nurses in lowering diet-induced coronary heart disease risk Br. J. Gen. Prac. 1997; 47: 7-11.

36 Imperial Cancer Research Fund OXCHECK Study Group. Effectiveness of health checks conducted by nurses in primary care: results of the OXCHECK study after one year. BMJ 1994; 309: 308-312.

37 Pritchard DA, Hyndman J, Taba F. Nutritional counselling in general practice: a cost effective analysis. J. Epidemiol. Com. Hlth 1999; 53: 311-316.

38 Adams JL, Fitzmaurice DA, Heath CM et al. A novel method of guideline devlopment for the diagnosis and managemement of mild to moderate hypertension. Br. J. Gen. Prac. 1999; 49: 175-179.

39 Thompson RL, Margetts BM, Speller VM, McVey D. The Health Education Authority's health and lifestyle survey 1993: who are the low fruit and vegetable consumers? J. Epidemiol. Com. Hlth 1999; 53: 294-299.

40 Stevens W, Hillsdon M, Thorogood M, McArdle D. Costeffectiveness of a primary care based physcial activity intervention in 45-74 year old men and women: a randomized controlled trial. Br. J. Sports Med. 1998; 32 236-241.

41 McKenna J, Naylor P-J, McDowell N. Barriers to physical activity promotion by general practitioners and practice nurses. Br. J. Sports Med. 1998; 32: 242-247.

42 McAvoy BR, Kaner EFS, Lock CA, Heather N, Gilvarry E. Our Healthier Nation: are general prcatitioners willing and able to deliver? A survey of attitudes to and involvement in health promotion and lifestyle counselling. Br. J. Gen. Prac. 1999; 49: $187-190$

43 Little P, Barnett J, Margetts BM, et al. The validity of dietary assessment in general practice. J. Epidemiol. Com. Hlth 1999; 53: $165-172$.

44 Roe L, Strong C, Whiteside C, Neil A, Mant D. Dietary intervention in primary care: validity of the DINE method of diet assessment. Family Practice 1994; 11: 375-381. 